\title{
Mining Region Environmental Management in Transition to Sustainable Development
}

\author{
Lucia Domaracká ${ }^{1, *}$, Marcus Torres $^{2}$, Nicolas Fonseca ${ }^{2}$, Anna Sokolova $^{3}$, and Maria \\ Yazevich $^{3}$ \\ ${ }^{1}$ Technical University of Kosice, Faculty of Mining, Ecology, Process Control and Geotechnologies, \\ Letná 9, 04200 Kosice, Slovak republic \\ ${ }^{2}$ Polytechnic University of Catalonia, 08860 Plaça de l'Església, 1, Barcelona, Spain \\ ${ }^{3}$ T.F. Gorbachev Kuzbass State Technical University, Department of history, philosophy and social \\ sciences, 65000028 Vesennya st., Kemerovo, Russia
}

\begin{abstract}
An adequate assessment of the environmental factor at the macro level is important in determining the direction of social-andeconomic development. Practically, at this level, there is a choice of a "sustainable" or "unsustainable" development. Underestimation of natural resources and environmental damage distorts the indicators of economic development and progress, which leads to the choice of an inefficient social-and-economic direction. If there is no mechanism of compensation for social-environmental-economic damage by the violator (implementation of the polluter pays principle), then this means that the corresponding losses are real for other economic agents and the population. To assess the relationship between the quantity and quality of economic growth, the trends of social-and-economic development of countries and regions, sustainability indicators are needed as targets for assessing the effectiveness of this development. The ecological imperative in sustainable development requires defining it (sustainable development) as the main goal of environmental policy at all levels. In Russia, the issues of environmental policy development at the federal level are worked out the best. At the regional and municipal levels, there are only a few positive examples of the development of environmental policy, including in the Kemerovo region.
\end{abstract}

\section{Introduction}

In Russia the features of environmental management have always been due to significant territorial differences in the allocation and use of natural resource potential. Since natural conditions and natural resources, as components of the natural resource potential, have always been, regardless of their number, a natural prerequisite for the development and distribution of productive forces, the methods of using them, the rate of depletion and dependence on this development of the economy have always been a topical problem in economic science. Depending on the place and role of the natural resource factor in the economy of the country or region, environmental management mechanisms are formed. In

\footnotetext{
* Corresponding author: domaracka.lucia@gmail.com
} 
modern Russia, improving the management system of regional environmental management has a special meaning, because the country's economy is based on raw materials, mainly fuel resources, which are localized in a number of regions. In these regions, a special economic policy is formed, which is correlated with the development strategy of the entire country. The peculiarities of regional nature management and the current economic situation in the country are the subject of a considerable number of studies. The peculiarities of regional nature management in Russia at the present stage are identified and grouped in the following way:

First, the industrial structure of production formed in previous periods has led to a distortion and excessive development of natural resources.

Second, the raw material specialization of the economy of these regions has not only economic but also political and environmental consequences, aggravating the inequality in their development.

Third, in terms of crisis, natural resources, like the "buffer", soften the severity of economic losses and allow filling budgets of all levels.

Fourth, the difficulty in determining the ownership of natural resources and the formation of a mechanism for the withdrawal of natural rents.

Fifth, regional economic and environmental policies are formed without taking into account the boundaries of ecosystems, etc.

\section{Materials and Methods}

At the present time and in the short term, despite the significant progress in reforming the economy of the regions (the formation of technical innovation zones, the declaration of avoidance of raw materials, etc.), economic growth will remain primary, i.e. extensive. The extensive type of economic development is characterized by high environmental intensity [1-3]. In terms of quality, the growth of environmental capacity is manifested in two aspects. First of all, there is a shortage of natural resources, which, in order to be recovered, additionally involve new natural resources in the production process (extensive expansion of the natural economy base). In addition, the limited capacity to attract new resources, which is now typical for most countries in the world, causes a sharp increase in the load on resources in use. The pollution of the environment is also growing. A frequent consequence of this in the conditions of maintaining the previous technological level is the gradual depletion and degradation of resources, the growth of pollution, which further exacerbates the economic situation in the commodity regions. The environmental factor is limiting their development. The economic complex of the raw materials regions has a significant negative impact on the environment. The mining industry development does not pass without a trace.

World practice has many examples where in conditions of a weakly stimulating economic mechanism, lack of strict environmental restrictions and requirements, environmental monitoring, industrial enterprises pollute water, destroy land, and "disappear" without carrying out restoration work to eliminate damage. The importance and complexity of the problems created by the mining industry dictates a long-term goaloriented policy based on the approved priorities for the development of natural resources, protection and restoration of territories, destroyed ecological systems, and the creation of a healthy living environment for the population. The end of the 20th century, perhaps, will remain in the social-and-economic history of the country and regions, as a period of the secondary formation of mining industries and increasing the natural resource intensity of the economy as a whole. It is clear that this growth is of poor quality and does not add sustainability to the regional development. In this regard, studies on assessing sustainability at the regional level in the context of priority development of the raw materials sectors are becoming topical. Natural resource intensity is an important indicator among the indicators 
of sustainable development at the regional level. This indicator is widely used by the authors in the development of environmental indicators for Russia and individual regions [4-5]. Practically in all systems of indicators of sustainable development for international organizations and individual countries various modifications of this indicator are widely represented. This indicator characterizes well the type and level of environmental and economic development.

To assess sustainability, two types of natural resource intensity indicators can be distinguished.

The first indicator is the unit costs of natural resources per unit of the final result (final output). Often this indicator is defined as the actual indicator of environmental intensity. Here, the value of the nature resource depends on the efficiency of its use in the whole chain that connects the primary natural resources, the products produced from them, and directly the final stages of the technological processes associated with the transformation of the natural substance.

The second indicator is the specific values of pollution per unit of the final result (final output). This indicator is also defined as the contamination intensity. Various contaminants, gases, wastes can be taken as impurities. The value of this indicator largely depends on the level of "waste-free" technology, the efficiency of treatment plants, etc.

At the level of the region, two levels of natural resource intensity indicators can be identified: the macro-level (the level of the entire regional economy) and the product and industry level. At the first level, this may be indicators of natural resource intensity, reflecting indicators at the regional level: the costs of natural resources (resource), the volume of emissions of pollutants and waste per unit of gross regional product. Measurements of these indicators can be made both in value (for example, in rubles / rub.) and in natural-value (for example, tons / rub: production (consumption) of oil per GRP unit) [6-8]. Separate natural resource intensity indicators cannot be used for assessing sustainability; they can demonstrate the extent of impact and extraction of natural resources or differences in interstate, interregional or sectoral scales of natural resource intensity. At the same time, they are important in the integrated assessment of environmental constraints using the indicator of the ecological capacity of the territory.

Determining the amount of damage from various pollutants is very laborious and is associated with methodological discrepancies. A simplified methodology for calculating damage from carbon dioxide emissions based on the cost of the global limit of $20 \$ /$ ton of carbon emissions was proposed by World Bank experts. Based on this methodology, in 2005 , carbon dioxide emissions from the coal industry of the Kemerovo region alone caused environmental damage of almost $\$ 2$ million. The coal industry differs from other industries in the extremely low level of capture and neutralization of polluting substances only $21 \%$, which is three times more than the average for the industries.

It should be noted that hydrocarbons are not captured by local treatment facilities at all. The reason for this situation is the weak material interest of mining enterprises in reducing emissions into the atmosphere. The existing basic standards used to calculate the regular environmental payments and the economic efficiency of air protection investments in the industry as a whole are insignificant.

\section{Results and Discussion}

Coal is the first regional product; therefore the competitiveness and investment attractiveness of the Kemerovo region, in the medium term, is determined by the successes in the coal industry. According to the Strategy of Sustainable Development of Russia, the territory of the Kemerovo region has the highest ( 7 th) rank of ecological tension. Here, over a considerable area, the economic capacity of ecosystems is exceeded and the further 
increase in production (with the existing level of technology and production structure) will lead to the final degradation of natural complexes, complete depletion of the resource base and the formation of hotbed of disease of the population. In the near future the environmental factor can become a constraint on economic growth for the region, reducing its investment attractiveness, and investment potential may directly depend on the depletion of coal reserves and the exhaustion of the ecological capacity of the territory. Raw materials in Kuzbass have, by a number of objective reasons, the limits of growth. At the same time, even the growth of their volumes several times will not allow the region to achieve significant GRP growth. The matter is that the mining enterprises are most subject to negative influence of the natural factor. They are moving to less developed and more complex areas for the development of subsoil resources.

Technical progress is not able to compensate the rise in price which occurs due to the environmental protective measures and, as experience shows, can significantly reduce the profit of the enterprise. Secondly, the impact on individual areas is very long and leads to irreversible consequences, for example, disease incidence and mortality of the population, the disappearance of natural landscapes and certain types of biodiversity. The only opportunity to provide growth is innovative technologies. The main direction of innovations in the Kemerovo region is the maximization of the use of natural resources, which should be understood in this case as the deepest use (processing) of natural resources. Resource-saving industries have incomparably greater opportunities to increase profitability. The decrease in costs is due to the increase in concentration and combination of production in its vertical and horizontal forms, resource saving, increasing the complexity of the use of raw materials, expanding the range of products and the emergence of leading products [7].

In this connection, the main task of innovative activity in Kuzbass is to transform the first regional product - coal into a primary resource. Unfortunately, the share of innovative products in total production remains insignificant and is $1.4 \%$, the share of processing industries oriented to the domestic market is only 3\% [5]. The peculiarity of the mining industry is that the negative impact occurs in a complex manner, simultaneously on all components of the environment - atmospheric air, water bodies, soil cover, biodiversity and public health.

Therefore, it would be advisable to turn our attention to the assessments of natural resource intensity and the impact on the environment of the region's territory, namely, made by the industry. The enterprises of the main branches of the regional economy - coal, ferrous and non-ferrous metallurgy, energy, Housing and Utilities infrastructure - are leading to the pollution of atmospheric air. The contribution of individual industries to air pollution is not the same.

Traditionally, the largest contribution - more than $40 \%$ - is made by the coal industry. Each extracted one million tons of coal is accompanied by the emission of more than 3 tons of pollutants. Pollution of the atmosphere is created during drilling and blasting operations, transportation, dusting of dumps and work of car engines. Disposed substances mostly fall to nearby areas, exacerbating an already tense situation with soil pollution and public health. Over the past five years, the volume of industrial production in the region has steadily increased. At the same time, emissions into the atmosphere increase too. Currently, they are more than 1.6 million tons per year (2009). The load per 1 inhabitant of the region is $469 \mathrm{~kg} /$ year. The difference in the indicators between the individual territories is enormous [5].

In the region the emissions in some cities reach $2,484 \mathrm{~kg}$ per year. The annual increase in this load can be up to $40 \mathrm{~kg}$ / person. Of particular concern is the increase in greenhouse gas emissions, such as carbon dioxide and methane. In 2005, their volume exceeded 9 million tons. Over the past four years, these emissions have increased by 1.57 and 1.52 
times, respectively. Greenhouse gases are mainly formed by burning coal and emissions from ventilation and degassing installations in mines [5].

The Kemerovo region is in the lead among all coal-mining and coal-consuming regions (12\% of all emissions). In addition, in the Kemerovo and Tyumen regions the highest specific indicators of greenhouse gas emissions per capita are more than 20 tons of $\mathrm{CO} 2$ per person and 1200-1650 tons of CO2 per 1 billion rubles GRP. In connection with Russia's ratification of the Kyoto Protocol, this is becoming a problem not only for environmentalists, but for the entire economy of the region. Another negative aspect of the emission of a large amount of methane, one of the main greenhouse gases, is the safety of miners. The accumulation of methane in large amounts in mine workings causes explosions and fires with tragic consequences for workers' lives. As a result of calculations of the maximum one-time atmosphere pollution by methane from a set of mines, it is established that in high wind speed the excess of the estimated safe level $(50 \mathrm{mg} / \mathrm{m} 3)$ in methane is observed by 50 times in their territory. Such territories are classified as catastrophic level of atmospheric air pollution [7].

The environmental situation in the areas of activities of coal mining enterprises is tense, the annual accumulation of solid coal mining and processing wastes continues, a large number of toxic components continue to be emitted and dispersed with sewage and waste gases, and also concentrate in dumps. Each thousand tons of underground mining is accompanied by the delivery of $110-150 \mathrm{~m} 3$ of rocks to the surface, one thousand tons of coal enrichment - storage of 100-120 m3 of rock [5]. Dumps of coal industry waste cause alienation of a significant amount of scarce land, pollution of groundwater, soil and air basin. At the same time, the number of the existing cleaning faces with the full and partial laying of the worked-out space in underground mining is practically insignificant. The methods of cleaning mine water, in particular, demineralization of brackish drains are being introduced slowly.

The tightening of legislation partially stimulates mining enterprises to reduce the land capacity of mining. In particular, the creation of internal dumps (in waste emptiness) reduces the land capacity by almost $30 \%$. The situation is complicated by the fact that more than half of the disturbed lands (more than 30 thousand hectares) remained from closed and being closed enterprises. The probability of their recovery in the coming decades is minimal. If we proceed from the current costs of reclamation of one hectare of disturbed land is 200 thousand rubles, then almost 6.5 billion rubles are needed. This amount will multiply if the environmental and economic damage is considered taking into account the natural and economic significance of soils and land resources and indexation factors. In this case, the norm of the cost of developing new lands in exchange for those that are rejected for non-agricultural purposes will increase to 1020 thousand rubles / ha. Annually more than 20 thousand hectares of land are disturbed in Kuzbass. The main load in this case again falls on the territory of Kuznetsk Basin. There is a danger of a radical disruption of the biological productivity of natural landscapes and a decrease in the productivity of agricultural lands. In addition, the population is deprived of the opportunity to use natural ecosystems for recreational purposes [5].

Considering the growing role of the coal industry in the Energy Strategy of the Russian Federation and the lack of modern innovative technologies at all stages of the technological chain in the coal sector, the main directions of the development are:

- deep processing of coal and coal waste;

- new technologies of coal mining;

- industrial safety;

- extraction and processing of methane from coal seams;

- new technologies in mining engineering;

- medicine, ecology, education. 
The interaction of business, science and the state can ensure state innovation policy. This requires a legislative package regulating private-public partnership in the development of innovation, which should form a competitive economy in the country as a whole. In the Kemerovo region, the beginning of this process was the adoption of the law in 2008 "On the innovation policy of the Kemerovo region".

The goal of the innovative policy of the Kemerovo region is the effective use of material, financial, intellectual, scientific and technical and other resources directed to the creation of science-intensive products and progressive technological processes. The main principle of innovation policy in the region is the integration of innovative, investment, scientific, scientific, technical and educational activities with a view to ensuring their integrated interaction with production. The implementation of the innovative policy in future should turn Kuzbass into the leading Russian center of the technological supply of the world's mining industry and radically improve the quality of life of the population in the region.

\section{Conclusion}

Ecologization of economic development of the region will be more successful in the conditions of stimulating enterprises to form an active environmental policy. Under the current economic mechanism of nature management, Russia has not yet developed a positive economic incentive for enterprises fulfilling eco-modernization of production. Active environmental policy of the enterprise is a policy of double winning - the negative impact on the environment and the resource component in production costs are reduced. The resource-saving policy is symmetrical in reducing the burden on the environment. The task is not simply to replicate the existing assets of the region, but to change their nature, increase mobility, reduce the size and make them more "intelligent", social in nature, that is, "converted" to the needs of the population. It is impossible to ignore the global development trends, according to which innovations become the source of sustainable growth. When developing a strategy for the development of the region, it is very important to establish a link between sustainable development and the rate of "true savings" in order to determine all possible ways to influence the strengthening of sustainability, from macroeconomic to purely ecological.

\section{References}

1. B. Aris, Europ. Lead. Net. Pol. Brief., 6, 25 (2014)

2. G. Mensch, Stalemate in technology: innovations overcome the depression (Cambridge, Masachusetts, 1979)

3. M. Rodrigues, J. Monet. Econ., 57: 2, 175-188 (2010)

4. K. Gawroński, K. Van Assche, J. Hernik, Infrastructure and Environment, 11, 53-70 (2010)

5. V. Trifonov, O. Loyko, D. Nesteruk, S. Zhironkin, E. Strekovtsova, AIP Conference Proceedings, 1800, 050009 (2017)

6. H. Molotch, Amer. J. Sociol., 82:2, 309-332 (1976)

7. A. B. Efremenkov, A. A. Khoreshok, S. A. Zhironkin, A. V. Myaskov, IOP Conference Series: Earth and Environmental Science, 50:1, 012009 (2017)

8. B. Sály, J. Janocko, S. Jacko, V. Jureňa, I. Hlavaty, New results in the mature east slovakian basin based on $3 D$ and $2 D$ seismic data interpretation and sequence stratigraphy, Society of Petroleum Engineers, 68th European Association of 
Geoscientists and Engineers Conference and Exhibition, incorporating SPE EUROPEC 2006 (EAGE, 2006) 